\title{
Pure oxy-fuel circulating fluidized bed combustion by controlling adiabatic flame temperature using fuel staging ${ }^{\dagger}$
}

\author{
Azd Zayoud, P. Mahanta* and U. K. Saha \\ Mechanical Engineering Department, Indian Institute of Technology Guwahati, Guwahati 781 039, India
}

In the present study, a new method is proposed for temperature controlling by combustion staging. Two combustion stages can be used with two stages of fuel feeding. A high stoichiometric ratio (SR) $\lambda>1$ is used at the first stage to mitigate adiabatic flame temperature (AFT) in case of high $\mathrm{O}_{2} \%$ in the oxidant. For validation, a series of experiments are conducted using mini-CFB (circulating fluidized bed), and an oxidant of $100 \% \mathrm{O}_{2}$ concentration is used with three SR ratios, i.e. $\lambda=1.25,2.0$ and 3.0. The resulting average temperatures along the riser for biomass are $1031^{\circ} \mathrm{C}, 950^{\circ} \mathrm{C}$ and $798^{\circ} \mathrm{C}$; and for coal $1129^{\circ} \mathrm{C}$, $1051^{\circ} \mathrm{C}$ and $961^{\circ} \mathrm{C}$ respectively. The controlling of AFT with pure oxy-fuel combustion eliminates the recycled flue gas in oxy-fuel CFB combustion and flue gas recirculation section; this simplifies design, fabrication and installing-operating costs of the power plants. Familiarizing this concept can accelerate adapting oxy-fuel combustion in CFB power plants for carbon capturing and sequestration. This study can help commercialize the third generation of oxy-fuel CFB combustion with zero RFG. Finally, the concept of controlling AFT by SR is validated experimentally.

Keywords: Adiabatic flame temperature, carbon capturing and sequestration, circulating fluidized bed, oxyfuel combustion.

IN both internal and external engines, controlling the combustion rate of heat release (RoHR) is essential to control the combustion parameters, namely temperature, emissions and power plant performance. Subsequently, controlling adiabatic flame temperature (AFT) is crucial in combustion engines. AFT affects engine emissions, viz. $\mathrm{NO}_{x}, \mathrm{CO}, \mathrm{CO}_{2}, \mathrm{SO}_{x}$, engine performance and combustion noise. In internal combustion engines (ICEs), combustion flame temperature can be controlled by exhaust gases recirculation (EGR) ${ }^{1}$. Multiple injection systems are successfully being used in ICEs with preinjection, post-injection and split-injection. Multiple in-

\footnotetext{
*For correspondence. (e-mail: pinak@iitg.ernet.in)

${ }^{\dagger}$ Revised version of the poster presentation at the 5th International Conference on Advances in Energy Research held on 15 December 2015, at the Indian Institute of Technology Bombay.
}

jection systems aim to control RoHR, AFT, $\mathrm{NO}_{x}$ and $\mathrm{SO}_{x}$. In this technique, the total injected fuel of each cycle is splitted into pre-injection, main-injection, post-injection, or multi-injections. In this case, the oxidant stoichiometric ratio $(\mathrm{SR} ; \lambda)$ and $\mathrm{RoHR}$ are controlled and accordingly AFT is controlled ${ }^{2-4}$. Moreover, water injection is used for enhancing the performance of ICEs and controlling flame temperature ${ }^{5}$.

On the other hand, in external combustion engines (ECEs) like power plants, recycled flue gas (RFG) is applied to control AFT. In oxy-fuel circulating fluidized bed (CFB) combustor, enhanced solid recirculation rate is used to enhance heat absorption and to control the flame temperature. The maximum used $\mathrm{O}_{2}$ concentration so far is $50 \%-70 \%$ (refs 6,7 ). In contrast, pure oxy-coal pulverized burners are installed and run to stabilize the flame, capture high concentration of $\mathrm{CO}_{2}$, and recover latent and sensible heat from the exhaust. The number of oxy-coal pulverized burners has now increased ${ }^{8,9}$. Earlier, excess air ratio was used to achieve staged combustion. Two techniques are used in a fixed bed, namely fuel staging and air staging ${ }^{10}$. In both cases, SR is used to control $\mathrm{NO}_{x}$ emissions. Air staging is used in furnaces, viz. downdraft, under-stoker, grate and fluidized bed ${ }^{11}$. To the best of our knowledge, fuel staging has never been used in CFBs.

To sum up, AFT is a function of oxygen concentration in the oxidant, the rate of heat release and reaction SR. This provides three techniques of controlling AFT in ICEs and ECEs (Table 1).

Moreover, controlling AFT is essential for oxy-fuel CFB combustion technique that is being accelerated by carbon capturing and sequestration (CCS) technology. Increasing oxygen concentration could be used to overcome the efficiency penalty of applying oxy-fuel CFB combustion $^{12,13}$. The main barrier of increasing oxygen concentration is the maximum temperature of the flame, which could exceed the design limits. Hitherto, researchers have been working on increasing the oxygen concentration for CFB with controlling of temperature by $\mathrm{CO}_{2}$ recirculation and enhancing solid recirculation to absorb the generated heat $^{14}$. Foster and Wheeler provided $30 \mathrm{MWth}$ CFB to the Fundacion Ciudad de la Energia (CIUDEN) ${ }^{15}$, which operates under oxy-fuel and air, with $\mathrm{O}_{2}$ concentration up to $30 \%$. The maximum oxygen concentration that has 
Table 1. Techniques of controlling the adiabatic flame temperature in combustion engines

\begin{tabular}{lll}
\hline \multirow{2}{*}{ Heat absorption } & \multicolumn{1}{c}{ Stoichiometric ratio $(\lambda)$ controlling } \\
\cline { 2 - 3 } Coolant controlling in ICE & \multicolumn{1}{c}{ Oxidant controlling } & Fuel feed controlling \\
Solid re-circulation controlling in ECE & $\begin{array}{l}\text { Controlling } \mathrm{O}_{2} \% \text { in ICE } \\
\text { Controlling } \mathrm{O}_{2} \%\end{array}$ & Multiple injection in ICE \\
& Gas staging in ECE & Fuel feed staging in ECE \\
\hline
\end{tabular}

ICE, Internal combustion engine; ECE, External combustion engine.

Table 2. Oxy-fuel circulating fluidized bed research groups working with several oxygen concentration levels

\begin{tabular}{|c|c|c|c|c|}
\hline Group & $\mathrm{MW}_{\text {th }}$ & Year & $\mathrm{O}_{2} \%$ & Reference \\
\hline ALSTOM & 3.0 & 2006 & $30-50$ & 16 \\
\hline University of Utah & 0.3 & 2009 & $21-33$ & 17 \\
\hline CANMET & 0.1 & 2010 & $60-70$ & 18 \\
\hline Czestochowa University of Technology & 0.1 & 2010 & 35 & 19 \\
\hline Metso Power Oy & 5 & 2011 & $16-36$ & 20 \\
\hline Wien Technical University & 0.1 & 2011 & 30 & 21 \\
\hline CIUDEN & 30 & 2012 & 30 & 15,22 \\
\hline VTT & 4 & 2013 & $21-25$ & 23 \\
\hline Southeast University & 0.05 & 2014 & $22-23$ & 24 \\
\hline Chinese Academy of Science & 0.1 & 2014 & 50 & 25,26 \\
\hline Chalmers & $0.1-4$ & 2015 & 70 & 14 \\
\hline
\end{tabular}

been achieved is $70 \%$ (ref. 14); RFG is still used to regulate the temperature of the CFB unit with augmented solid recirculation rate (SRR). This enriched oxy-combustion technique has many advantages, viz. compactness, utilizing low rank of fuel, improved temperature stability and heat transfer, increased efficiency due to minimizing exhaust gas flue and lower emissions. Therefore, as shown in Table 2 (refs 16-26) the oxygen concentration in CFB combustor is being gradually increased with time.

Moreover, oxy-fuel CFB combustion has advantages over oxy-fuel pulverized fuel combustion, viz. uniform temperature, in situ desulphurization, high combustion efficiency, low nitric oxide $\left(\mathrm{NO}_{x}\right)$ emissions and fuel flexibility. Besides, there is no need of new combustors for oxy-fuel CFB combustion in contrast with oxy-fuel pulverized case $^{26}$. Up to now, more than 1000 industrial and pulverized coal furnaces have converted from aircombustion mode to oxy-combustion without $\mathrm{RFG}^{27}$; also using pure oxygen combustion could help save 10\%-70\% fuel $^{28}$. To the best of our knowledge, there is no single CFB power plant operating under pure oxygen condition.

In this study, we aim to use pure oxygen for oxy-CFB combustion, with new temperature controlling method for CFBs depending on combustion staging by fuel staging rather than using RFG. Fuel staging allows controlling combustion and varying SR. At the first stage, the used oxidant is $100 \% \mathrm{O}_{2}$, and fuel is fed to achieve high SR more than $100 \%$, where the excess oxidant absorbs heat and does not take a part in the reaction. The fuel gases of the first stage is rich in $\mathrm{O}_{2}$ and subsequently it is used as an oxidant for the second stage. The method and experimental results are described below.

\section{Hypothesis}

For any combustion reaction, the oxidant fuel ratio (OFR) is defined as the mass of the required oxidant for ideal combustion to the mass of the fuel

$$
\mathrm{OFR}=\frac{m_{\text {oxidant }}}{m_{\text {fuel }}}
$$

where $m_{\text {oxidant }}$ and $m_{\text {fuel }}$ represent the mass of the oxidant and fuel respectively. The combustion is stoichiometric, when the fuel is oxidized perfectly without excess or shortage of oxidant; and OFR is represented as OFR stoich. $_{\text {. }}$ For instance, eq. (2) shows a stoichiometric reaction where $12 \mathrm{~kg}$ of carbon reacts perfectly with $32 \mathrm{~kg}$ of $\mathrm{O}_{2}$ to form $44 \mathrm{~kg}$ of $\mathrm{CO}_{2}$. In this case, OFR is stoichiometric

$$
\mathrm{C}+\mathrm{O}_{2} \rightarrow \mathrm{CO}_{2}
$$

In light of OFR definition, we may define $\mathrm{SR}$ as the ratio of OFR to OFR $_{\text {stoich }}$ as shown in eq. (3)

$$
\lambda=\frac{\mathrm{OFR}}{\mathrm{OFR}_{\text {stochio }}} .
$$


As shown in Figure 1, theoretically for carbon combustion, AFT of $100 \%$ oxygen concentration in the oxidant at $\lambda=5$ is almost the same as in the case of $21 \%$ oxygen concentration in the oxidant at $\lambda=1$. Figure 1 illustrates the effects of oxygen percentage in the oxidant (a mixture of $\left.\mathrm{O}_{2}-\mathrm{N}_{2}\right)$ with a range $\left(21 \%-100 \% \mathrm{O}_{2}\right)$ over the AFT of carbon combustion, with varied SRs (1-5). These AFTs are calculated for non-equilibrium reaction of carbon with oxygen. Dissociation effect at high temperature is neglected here for the sake of simplification.

In all cases, increasing SR decreases AFT, since the excess oxygen absorbs heat energy; it is unlike the reacted oxygen which takes part in the exothermic reaction. We suggest controlling AFT by SR rather than applying RFG. Figure 2 shows the proposed process for planned pure oxy-fuel combustion. The process starts in the first reactor with pure oxygen as oxidant and fuel that react under conditions of oxygen SR of $\lambda=3$. Then, the products of the first stage are mixtures of $\mathrm{CO}_{2}-\mathrm{O}_{2}$ and these are used as an oxidant for the second stage, where the combustion takes place with oxygen SR of $\lambda=2$. In the same manner, the fuel and oxidant react to produce $\mathrm{CO}_{2}$. This thermodynamic principle is the basis of controlling AFT and minimizing the exhaust flow rate. As a result, the overall efficiency is enhanced. SR itself is controlled by the feeding of fuel as explained below.

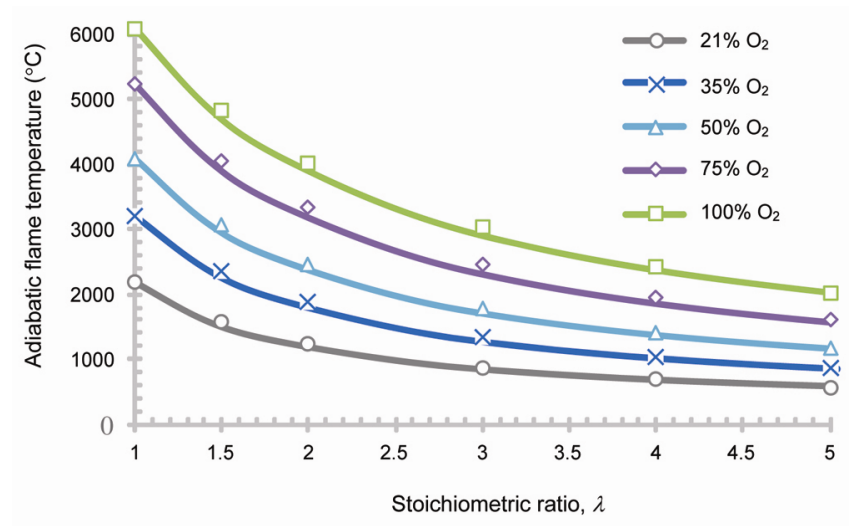

Figure 1. Estimated adiabatic flame temperature for air and oxycombustion with different oxygen concentrations and stoichiometric ratios.

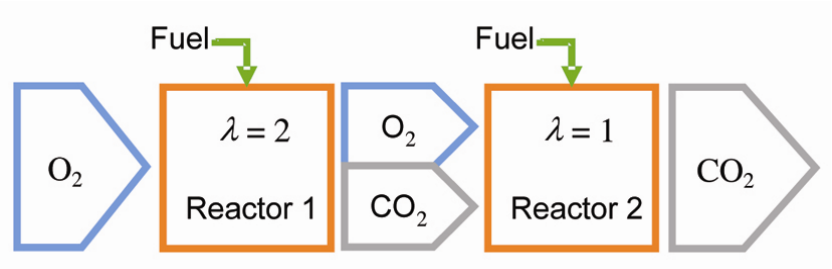

Figure 2. Schematic diagram of the proposed process for pure oxyfuel circulating fludized bed combustion.
The proposed method of controlling combustion by SR can be applied by using fuel feeding arrangement for a series of two mini-CFBs as shown in Figure 3.

On the other hand, heat absorbed by the water jacket, radiation and convection sections decreases the temperature. This technique can be used side by side with a high solid recirculation rate of inventory (sand) to control the temperature in the CFB. The primary flow of the series of mini-CFBs is pure oxygen that enters the first mini-CFB, where combustion of fuel takes place under oxygen SR of $\lambda=2$. The fuel gases of the first mini-CFB are enriched with oxygen, and these flue gases are forwarded to the second mini-CFB to react with an amount of fuel to meet SR of $\lambda=1$. For the sake of simplicity, the two stages of the series of mini-CFBs are simulated using a single mini-CFB. In the following sections, the experimental set-up, results and discussion are explained to validate the suggested hypothesis.

\section{Experimental set-up and procedure}

Figure 4 shows the CFB unit used to conduct experiments. The mini-CFB is made up of stainless steel 415. It has a riser of $2000 \mathrm{~mm}$ height and $54 \mathrm{~mm}$ internal diameter (ID). Along the riser eight thermocouples ( $K$-type) are fitted at different levels from the distributor plate as follows: 50, 250, 350, 500, 750, 1000, 1500 and $2000 \mathrm{~mm}$. Two thermocouples are fitted at the top and bottom of the stand pipe, which has an ID of $19 \mathrm{~mm}$. Aerocyclone with rectangular inlet is connected to the exit of the riser. Return leg is connected to the bottom of the riser at $25 \mathrm{~mm}$ from the distributor plate. A screw fuel feeder is fitted to feed fuel to the riser through return-leg; the electric driving motor speed and hence the feeding rate are controlled by a dual regulator power supply $(0-30 \mathrm{~V}, 0-5 \mathrm{~A})$. A preheater is fixed before the riser and an auxiliary external heater is fixed along the riser height. The riser is insulated by ceramic wool of $150 \mathrm{~mm}$ thickness. A mixture of

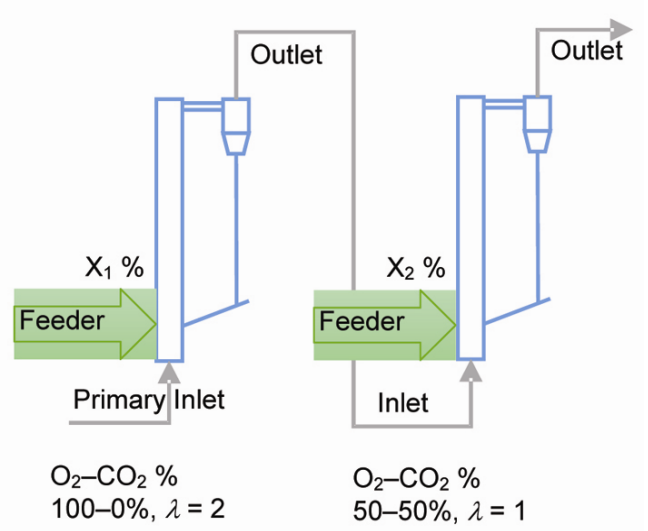

Figure 3. Arrangement of fuel feeding with a series of mini-CFBs for pure oxy-combustion.

CURRENT SCIENCE, VOL. 113, NO. 8, 25 OCTOBER 2017 
bottled $\mathrm{O}_{2}$ and $\mathrm{CO}_{2}$ (primary mixture) is supplied to the riser, controlled by rota-meters and valves, and heated using preheater during start-up. Pure $\mathrm{CO}_{2}$ is supplied as aeration for safety purpose and to avoid oxidant leakage to the fuel feeder.

\section{Precautions while conducting the oxy-fuel experiments}

It is highly recommended to use $\mathrm{CO}_{2}$ for aeration for safety purpose. Neither air nor $\mathrm{O}_{2}-\mathrm{CO}_{2}$ mixture is accepted for this design where the feeder is connected to the return-leg where the aeration flow takes place. If the aeration flows back to the feeder, it may cause a fire.

Start-up the set-up with air primarily, then switch to oxy-fuel combustion condition. Lastly, it is necessary to switch down the unit using air to wash the remaining $\mathrm{O}_{2}-\mathrm{CO}_{2}$ mixture. The same procedure is followed for CIUDEN Oxy-CFB boiler ${ }^{15}$.

The feeding of fuel shall be started after reaching the ignition temperature. This to avoid the accumulation of fuel in the reactor and thus prevent an explosion.

We have categorized the experiments into groups as follows, and the same procedure is repeated for each experiment with different fuel feeding rates, and $\mathrm{O}_{2}-\mathrm{CO}_{2}$ mixture percentages.
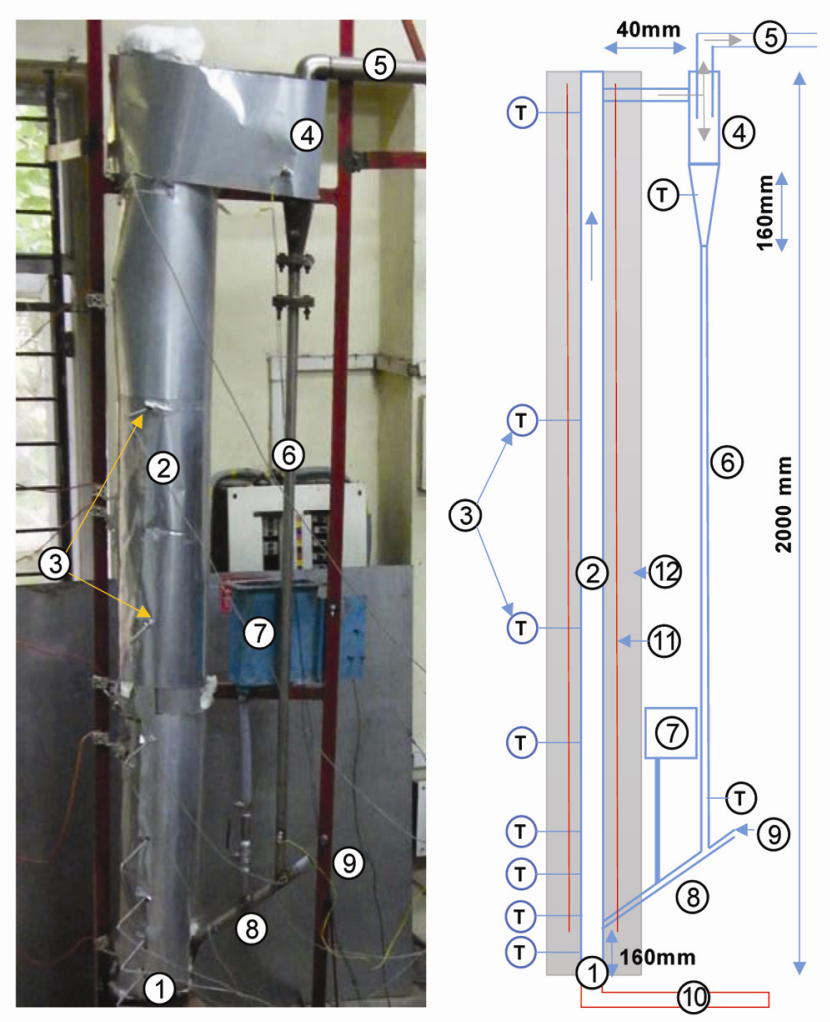

Figure 4. Photograph and sketch of the hot CFB unit. 1, Distributor plate; 2, Riser; 3, Thermocouples; 4, Aero-cyclone separator; 5, Exhaust outlet; 6 , Stand pipe; 7, Feeder; 8 , Return leg; 9, Aeration inlet; 10, Pre-heater; 11, Riser heater; 12, Thermal insulation.

\section{Oxy-fuel CFB combustion experiments matrix}

Two types of fuel are used - biomass (sawdust) and coal (bituminous). A temperature of $650^{\circ} \mathrm{C}$ is maintained to start-up the unit with biomass fuel (sawdust) of particle size from 0.5 to $1.0 \mathrm{~mm}$; and Assam bituminous coal of particle size from 0.8 to $1.7 \mathrm{~mm}$. The mixture concentrations of $\mathrm{O}_{2}-\mathrm{CO}_{2}$ are controlled by rotameters, and atmospheric pressure is maintained using regulators. Both fuel and inventory (sand of $160 \mu \mathrm{m}$ particle size) are fed using a screw feeder connected to the return-leg; an inventory of $750 \mathrm{~g}$ is used. Air is used for heating the unit during starting-up; then a mixture of $\mathrm{O}_{2}-\mathrm{CO}_{2}$ is used directly. The temperature profile along the riser is measured continuously using data acquisition and a series of $K$-type thermocouples fitted along the riser. In all cases, $\mathrm{CO}_{2}$ aeration of $0.25 \times 10^{-3} \mathrm{~m}^{3} / \mathrm{s}$ is used to entrain fuel and sand particles into the riser, without the risk of oxidant leakage to the feeder. The primary flow rate is fixed at $3.0 \times 10^{-3}$ normal m $3 / \mathrm{s}$ for $1.5 \mathrm{~m} / \mathrm{s}$ superficial velocity at grid level. In two stages, several scenarios of SRs in each stage could be applied, viz. $\lambda=3.0,2.0$ and 1.25. At the end of these stages, the aim is to get as perfect as possible combustion with minimum excess oxidant. In the following, three cases with three different SRs are explained.

(a) The first case is simulated using the mini-CFB of $2 \mathrm{~m}$ height set-up with pure oxygen primary inlet. This stage is sensitive since pure oxygen is used. Therefore, we have varied the SR, i.e. $\lambda=3.0,2.0$ and 1.25 . This is to optimize the fuel feeding rate to reach the desired working temperature of CFB, which is $800^{\circ} \mathrm{C}$ to $950^{\circ} \mathrm{C}$ in general. In other words, the excess oxidant is taken 2.0, 1.0 and 0.5 for mitigating temperature. Two groups of experiments are conducted: first using biomass (sawdust) and then using coal (Assam bituminous). SR is varied for each group as follows: $\lambda=3.0,2.0$ and 1.25.

(b) The second case is simulated using the mini-CFB of $2 \mathrm{~m}$ height set-up with $2 / 3 \mathrm{O}_{2}$ concentration and $1 / 3$ $\mathrm{CO}_{2}$ as a primary inlet and fuel feeding to meet the SR of $\lambda=2$. Two types of fuel are used: biomass (sawdust) and coal (Assam bituminous). Also, the same procedure as in the first case is used in terms of heating up, feeding fuel and inventory.

(c) The third case is simulated using the mini-CFB of $2 \mathrm{~m}$ height set-up with $1 / 3 \mathrm{O}_{2}$ concentration and $2 / 3 \mathrm{CO}_{2}$ as a primary inlet and fuel feeding to meet the SR of $\lambda=1$.

In all cases, a static mixer is used to mix $\mathrm{O}_{2}$ and $\mathrm{CO}_{2}$, and pure $\mathrm{CO}_{2}$ aeration flow is used. Table 3 shows the cases of experiments with percentages of the mixture and the $\mathrm{SR}$ for the mini-CFB. The rate of solid recirculation is in the range $15-20 \mathrm{~kg} \mathrm{~m}^{-2} \mathrm{~s}^{-1}$.

The exhaust gases are cooled down by water tubular heat exchanger, filtered, and sampled by using Tedlar bags. Gas chromatography is used to analyse the gaseous samples. The main aim here is to verify the feasibility of 


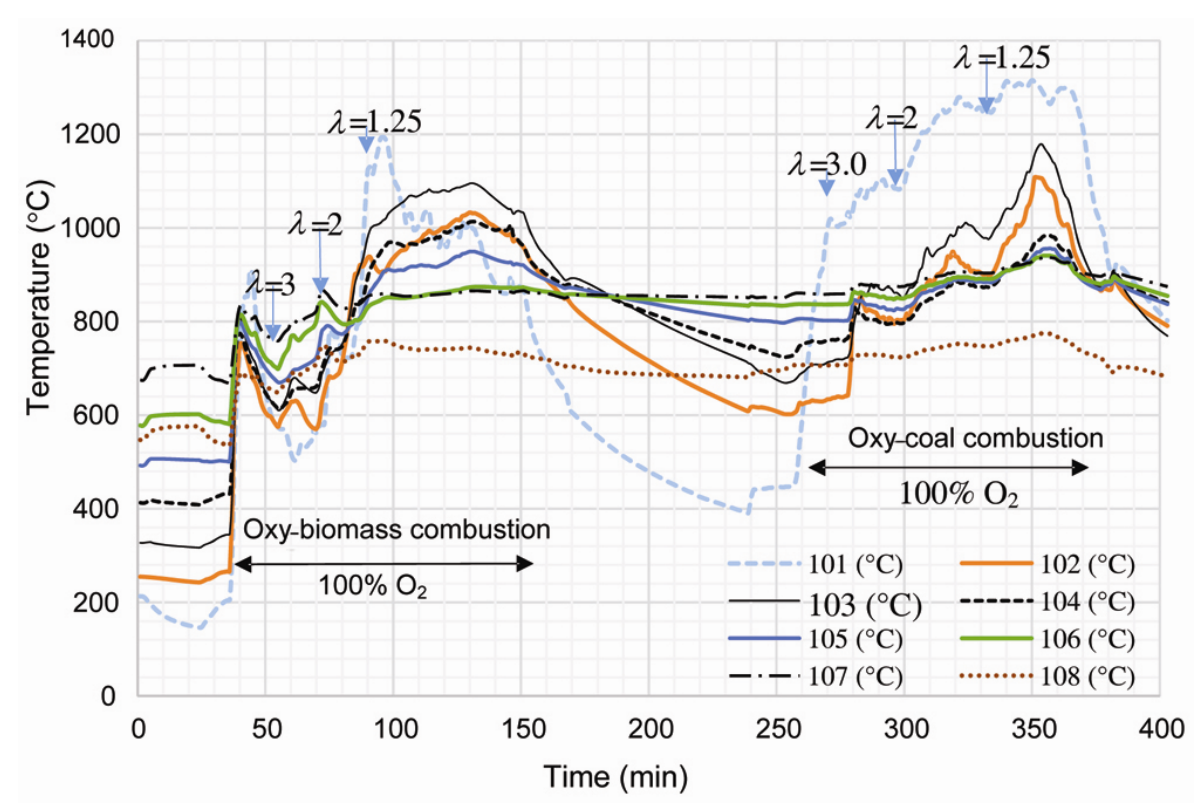

Figure 5. Variation of temperature along the riser for different fuel types and conditions with time.

Table 3. Experimental parameters for pure oxy-fuel CFB combustion $\left(100 \% \mathrm{O}_{2}\right)$

\begin{tabular}{llll}
\hline Case & $\mathrm{O}_{2} / \mathrm{CO}_{2} \%$ & $\lambda$ & Fuel \\
\hline 1 & $100 \%-0 \%$ & 1.25 & Sawdust \\
2 & $100 \%-0 \%$ & 2.0 & Sawdust \\
3 & $100 \%-0 \%$ & 3.0 & Sawdust \\
4 & $100 \%-0 \%$ & 1.25 & Bituminous \\
5 & $100 \%-0 \%$ & 2.0 & Bituminous \\
6 & $100 \%-0 \%$ & 3.0 & Bituminous \\
\hline
\end{tabular}

using pure oxygen as an oxidant for oxy-fuel CFB combustion.

\section{Results and discussion}

\section{Results of CFB combustion under pure $\mathrm{O}_{2}$ concentration}

Figure 5 illustrates the variation of temperature along the riser starting with pure oxy-biomass combustion case followed by pure oxy-coal combustion with three different SR values, and finally shutting down with air combustion. The thermocouples along the riser are numbered from 101 up to 108 , the numbering starts at the bottom and moving towards the upper portion.

A lower SR of $\lambda=1.25$ leads to higher temperature at the level of return-leg port $\left(1031^{\circ} \mathrm{C}\right)$. Since the rate of heat release is higher where instant combustion occurs at the bottom due to lower ignition temperature of biomass. In contrast, increased SR leads to lower temperature along the riser. The average temperatures along the riser (oxy-biomass $\mathrm{CFB}$ combustion case) are $1031^{\circ} \mathrm{C}, 950^{\circ} \mathrm{C}$ and $798^{\circ} \mathrm{C}$ for $\lambda=1.25,2.0$ and 3.0 respectively (Figure 5).
In the oxy-coal CFB combustion case, the highest temperature level is located at the bottom of the riser, and temperature increases with the increased coal mass flow rate and lower SR. The average temperatures along the riser (oxy-coal CFB combustion case) are $1129^{\circ} \mathrm{C}$, $1051^{\circ} \mathrm{C}$ and $961^{\circ} \mathrm{C}$ for $\lambda=1.25,2.0$ and 3.0 respectively. As a result, controlling SR leads to the regulation of RoHR and subsequently AFT. For both coal and biomass, as predicted, the temperature is maximum under $\lambda=1.25$ condition, and it consequently decreases under $\lambda=2.0$ and $\lambda=3.0$. Additionally, it is recognized that, the variation in temperature along the bottom portion of the riser is more than that at the upper portion, since the reaction takes place mainly at the lower portion. In contrast, temperature at the upper portion is lower as measured by thermocouples (nos 105, 106, 107 and 108). The coal and biomass CFB combustion results are explained in Figure 5.

The pure oxy-biomass combustion under $100 \% \mathrm{O}_{2}$ and SR of $\lambda=1.25$ results in the temperature profile as shown in Figure 6, where the moderated temperature variation through the riser height is pertained to distributed combustion along the riser. The highest temperature $\left(\sim 1200^{\circ} \mathrm{C}\right)$ is located directly at the level of feeding port; the lowest temperature is $900^{\circ} \mathrm{C}$ and the average value is $1150^{\circ} \mathrm{C}$ along the riser. Interestingly, the concentration of $\mathrm{CO}_{2}$ at the outlet is quite high $(76.8 \%)$, the excess $\mathrm{O}_{2}$ is $20.7 \%$, which is necessary to control SR, and $\mathrm{N}_{2}$ is $2.5 \%$. The same trend of temperature profile is found for SR of $\lambda=2$ and 3 , and average temperature of $950^{\circ} \mathrm{C}$ and $800^{\circ} \mathrm{C}$. There is no $\mathrm{CO}$ detected by gas chromatography (Figure 7). This finding agrees with results of Tondl et $a l^{21}$, where the concentration of CO increased from 1200 to below than $200 \mathrm{mg} / \mathrm{MJ}$ for increased $\mathrm{O}_{2}$ from $3.9 \%$ to $10 \%$.

CURRENT SCIENCE, VOL. 113, NO. 8, 25 OCTOBER 2017 


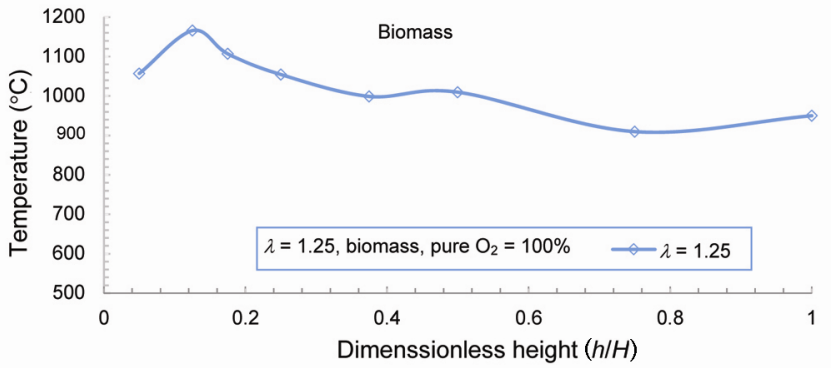

Figure 6. Variation of temperature along the riser with pure oxybiomass combustion $\lambda=1.25$.

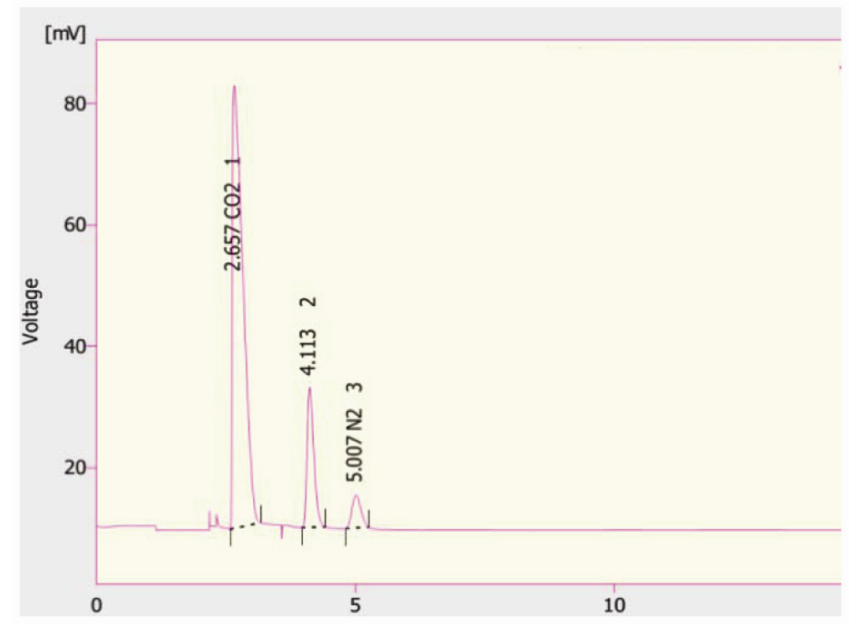

Figure 7. Sample of gas chromatography analysis report.

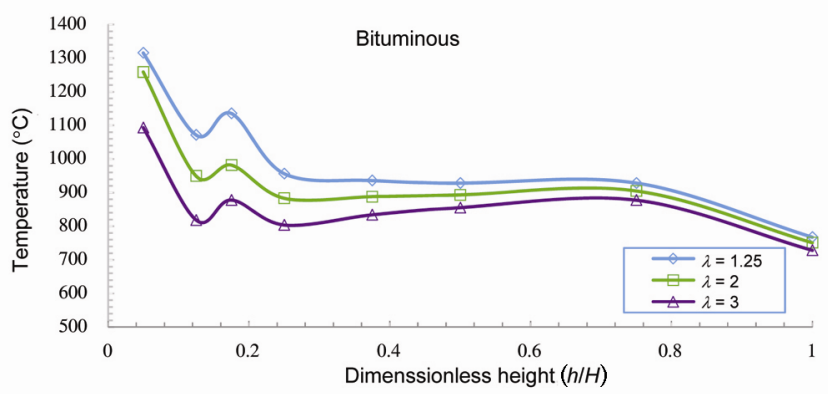

Figure 8. Variation of temperature profile with stoichiometric ratio along the riser height for coal fuel.

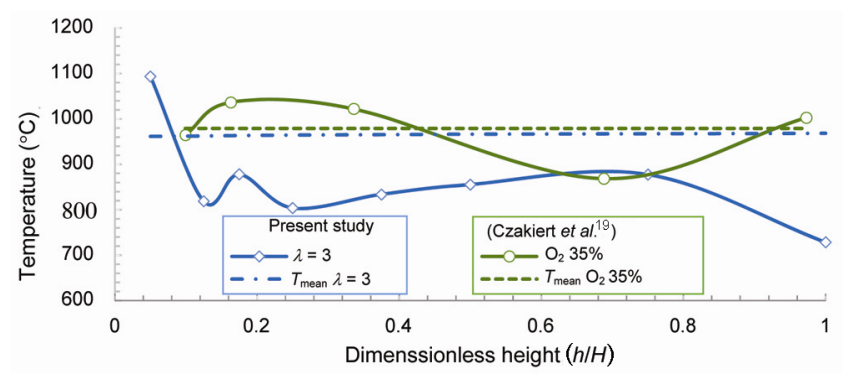

Figure 9. Comparison of temperature profile with the results of Czakiert et al. ${ }^{19}$
Figure 8 illustrates the effect of SR, viz. $\lambda=3.0,2.0$ and 1.25 on the bed temperature profile in case of pure oxy-coal combustion.

In all cases, the temperature profile starts with a high peak of more than $1100^{\circ} \mathrm{C}$ and gradually decreases. A significant drop in temperature is found at the level of the aeration entrance. This pertains to the lower temperature of aeration $\left(\sim 5^{\circ} \mathrm{C}\right)$ which flows directly from the cylinder of $\mathrm{CO}_{2}$ without pre-heating. Additionally, the temperature profile is found almost uniform at the medium height of the riser, where the temperature drops from $900^{\circ} \mathrm{C}$ to $700^{\circ} \mathrm{C}$ at the exit which is not insulated.

From the temperature profile, it can be inferred that, combustion takes place mainly at the bottom of the riser. This pertains to the higher terminal velocity of the coal particles (diameter of particles, $d_{p}=0.85-1.70 \mathrm{~mm}$ ) compared to the used superficial velocity $U=2.0 \mathrm{~m} / \mathrm{s}$. As a result, coal particles at the early stages of combustion (drying, devolatilization, ignition) keep fluctuating at the bottom till they lose sufficient weight by reaction and obtain lower terminal velocity to rise up (the terminal velocity of $1.0 \mathrm{~mm}$, coal particle size is $2.0 \mathrm{~m} / \mathrm{s}$ ).

In 2010, Czakiert et al ${ }^{19}$ conducted enhanced oxy-fuel CFB combustion experiment. They used coal particle size of $1 \mathrm{~mm}$ and superficial velocity of $\sim 4.85 \mathrm{~m} / \mathrm{s}$. In Figure 9 , the temperature profile for $\mathrm{O}_{2}$ concentration of $35 \%$ is compared with the result of the present study for $\lambda=3.0$. The higher superficial velocity leads to more uniform temperature profile along the rise, in comparison with the present study where we have used coal particle size of $0.85-1.70 \mathrm{~mm}$ and terminal velocity $U_{\mathrm{tr}}=1.8-2.8 \mathrm{~m} / \mathrm{s}$ (ref. 19). In both studies the temperature profile has almost the same average temperature, about $\sim 970^{\circ} \mathrm{C}$.

In contrast with pure oxy-coal CFB combustion, the temperature profile along the riser for pure oxy-biomass CFB combustion shows a peak at the aeration port level (Figure 10). This is because of the instant firing of the biomass particles, which have lower ignition temperature compared to coal, and lower terminal velocity of biomass.

These results optimize the SR for the first stage of pure oxy-fuel CFB combustion. SR of $\lambda=3.0$ is considered as

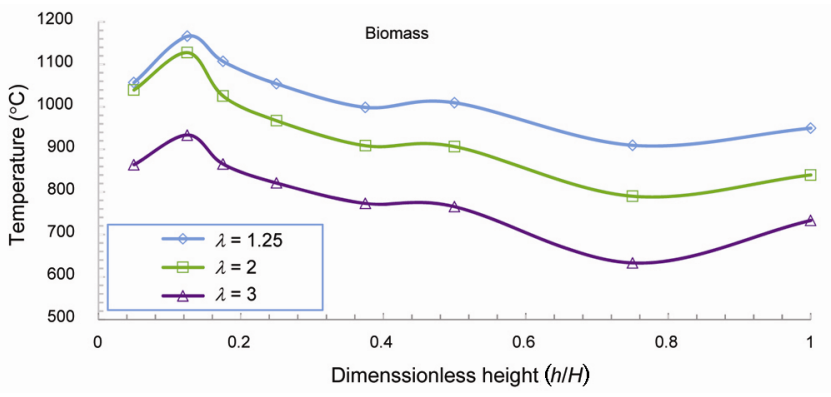

Figure 10. Variation of the temperature profile with $\lambda=1.25,2$ and 3 along the riser height for biomass fuel. 
the best value to achieve the required temperature in range $700-800^{\circ} \mathrm{C}$. SR of $\lambda=2.0$ could be used for two stages of pure oxy-fuel CFB combustion arrangements. The pure oxy-fuel CFB combustion could minimize the cost of power plant by compacting the set-up and enhancing the overall efficiency ${ }^{14,20}$.

This technique could provide an opportunity for the third generation of oxy-fuel CFB combustion with higher efficiency. So far, to the best of the our knowledge, there is no pure oxy-fuel $\mathrm{CFB}$ combustion; the highest value used was $60 \%$ and $70 \% \mathrm{O}_{2}$ concentration $^{6,14,20}$, where external fluidized heat exchanger was used with enhanced recirculation rate to absorb the released heat. However, the cost of installing and operating cost of recirculation set-up persist. Our proposed method eliminates the recirculation set-up and cuts down the cost of power plant as well as the operating cost, compacting the CFB power plant and cuts down the overall cost of the set-up. So far, the experimental results using mini-CFB are promising; further experiments using pilot scales are required for using the technique in industrial applications.

\section{Conclusion and future work}

A novel concept for pure oxy-combustion in CFB power plant has been proposed and subjected to experiments. Controlling temperature using SR is promising for pure oxygen combustion. High solid recirculation rate can be used to control and mitigate heat release of oxy-fuel combustion for future generation. Consequently, the overall cost of installing and operating CFB power plants can be minimized using this concept, where RFG set-ups and cost of operating are being avoided. Besides, avoiding $\mathrm{CO}_{2}$ recirculation improves the efficiency of combustion. This is in agreement with the results of Duan et al. ${ }^{29}$. The proposed pure oxy-fuel combustion provides the opportunity for future generation of oxy-fuel combustion in CFB power plants. We may conclude the following.

- $\lambda=3.0$ is considered as a good value to achieve the required temperature in the range of $700-800^{\circ} \mathrm{C}$. It is recommended to use $\lambda=2.0$ with enhanced heat absorption by higher SRR and external heat exchanger.

- Increased SR from 1.25 to 3.0 decreases the median AFT from $1031^{\circ} \mathrm{C}$ to $798^{\circ} \mathrm{C}$ in biomass case; and from $1129^{\circ} \mathrm{C}$ to $961^{\circ} \mathrm{C}$ in coal case.

- The arrangement of two-stages of mini-CFBs can be used for co-combustion of several types of fuel such like coal and biomass. Likewise, bubbling beds could use this arrangement of combustion staging like CFBs.

- Two stages of two connected CFBs with oxidant of $100 \% \mathrm{O}_{2}$ concentration is more economical compared with two CFBs running under oxy-fuel combustion separately with oxidant of $50 \% \mathrm{O}_{2}$ concentration; this is because half of the auxiliary set-ups is eliminated in the first case.
- It is highly recommended to use air for starting-up and switching-off the $\mathrm{CFB}$, to ensure that there is no $\mathrm{O}_{2}$ remaining at the starting-up of the next run; and using $\mathrm{CO}_{2}$ only in case of entraining the fuel from hopper to the reactor to avoid oxidant leakage into the full hopper.

- In the present study, we have conducted short-term tests. However, long-term tests should be done to examine problems like corrosion in CFB due to $\mathrm{SO}_{x}, \mathrm{NO}_{x}$ and their formed acids. As a result, the long-term tests are required to promote oxy-fuel CFB combustion and the proposed technique commercially.

- The preliminary laboratorial findings show a promising improvement in efficiency. Still, a comprehensive economic analysis of the pure oxy-fuel CFB combustion needs to be carried out for the promotion of this technology. Therefore, a cost analysis may be executed by considering various economic terms, and finding the set-up costs and operating costs under new conditions. The performance and emission study along with the economic assessment can provide a clear comparison between the pure oxy-fuel CFB combustion and the conventional oxyfuel CFB combustion. And, this study shows promising results of pure oxy-fuel CFB combustion, that may lead to industrial applications.

1. Ambrosio, S. and Ferrari, A., Effects of exhaust gas recirculation in diesel engines featuring late PCCI type combustion strategies. Energy Convers. Manage., 2015, 105, 1269-1280.

2. Cung, K., Moiz, A., Johnson, J., Lee, S.-Y., Kweon, C.-B. and Montanaro, A., Spray-combustion interaction mechanism of multiple-injection under diesel engine conditions. Proc. Combust. Inst., 2015, 35, 3061-3068.

3. Finesso, R. and Spessa, E., Ignition delay prediction of multiple injections in diesel engines. Fuel, 2014, 119, 170-190.

4. Hiwase, S. D., Moorthy, S., Prasad, H., Dumpa, M. and Metkar, R. M., Multidimensional modeling of direct injection diesel engine with split multiple stage fuel injections. Procedia Eng., 2013, 51, 670-675.

5. Wu, Z., Yu, X., Fu, L., Deng, J., Hu, Z. and Li, L., A high efficiency oxyfuel internal combustion engine cycle with water direct injection for waste heat recovery. Energy, 2014, 70, 110-120.

6. Bolea, I., Romeo, L. M. and Pallarès, D., Heat transfer in the external heat exchanger of oxy-fuel fluidized bed boilers. Appl. Therm. Eng., 2014, 66, 75-83.

7. Seddighi, S., Pallarès, D., Normann, F. and Johnsson, F., Heat transfer in a 4-MWth circulating fluidized bed furnace operated under oxy-fired and air-fired conditions: modeling and measurements. Int. J. Greenhouse Gas Control, 2015, 37, 264-273.

8. Ochs, T., Oryshchyn, D., Woodside, R. and Summers, C., Results of initial operation of the Jupiter Oxygen Corporation oxy-fuel 15 MWth burner test facility. Energy Procedia, 2009, 1, 511-518.

9. Schoenfield, M., Jupiter oxygen. In IEA GHG 1st Oxyfuel Combustion Conference, Cottbus, Germany, 2009, pp. 1-45.

10. Salzmann, R. and Nussbaumer, T., Fuel staging for $\mathrm{NO}_{x}$ reduction in biomass combustion: experiments and modeling. Energy Fuels, 2001, 15, 575-582.

11. Nussbaumer, T., Combustion and co-combustion of biomass: fundamentals, technologies, and primary measures for emission reduction. Energy Fuels, 2003, 17, 1510-1521.

12. ya Nsakala, N. et al., Oxygen-fired circulating fluidized bed boilers for greenhouse gas emissions control and other applications. In 
Third Annual Conference on Carbon Capture and Sequestration, Alexandria, Virginia, USA, 2004, pp. 1-21.

13. US Department of Energy, Improving Process Heating System Performance: A Sourcebook for Industry, Berkeley, California, 2007.

14. Seddighi, S., Pallarès, D., Normann, F. and Johnsson, F., Heat extraction from a utility-scale oxy-fuel-fired CFB boiler. Chem. Eng. Sci., 2015, 130, 144-150.

15. Lupion, M., Alvarez, I., Otero, P., Kuivalainen, R., Hotta, A. and Hack, H., 30 MWth CIUDEN oxy-CFB boiler - first experiences. Energy Procedia, 2013, 37, 6179-6188.

16. Liljedahl, G., Turek, D., ya Nsakala, N., Mohn, N. and Fout, T., Alstom's oxygen-fired CFB technology development status for $\mathrm{CO}_{2}$ mitigation. In 31 st International Technical Conference on Coal Utilization and Fuel Systems, Sand Key Island, Florida, United States, 21 to 26 May 2006.

17. Eddings, E. G. and Okerlund, R., Pilot scale evaluation of oxycoal firing in circulating-fluidized bed and pulverized coal-fired test facilities. In 1st Oxyfuel Combustion Conference, Cottbus, Germany, 2009.

18. Jia, L., Tan, Y. and Anthony, E. J., Emissions of $\mathrm{SO}_{2}$ and $\mathrm{NO}_{x}$ during oxy-fuel CFB combustion tests in a mini-circulating fluidized bed combustion reactor. Energy Fuels, 2010, 24, 910-915.

19. Czakiert, T., Sztekler, K., Karski, S., Markiewicz, D. and Nowak, W., Oxy-fuel circulating fluidized bed combustion in a small pilot-scale test rig. Fuel Process. Technol., 2010, 91, 1617-1623.

20. Seddighi, S., Pallarès, D. and Johnsson, F., Assessment of oxyfuel circulating fluidized bed boilers - modeling and experiments in a $5 \mathrm{MW}$ pilot plant 5-7. In 2nd IEA GHG International Oxyfuel Combustion Conference, Queensland, Australia, 2011.

21. Tondl, G., Penthor, S., Wöß, D., Pröll, T., Höltl, W., Rohovec, J. and Hofbauer, H., From oxygen enrichment to oxyfuel combustion. In 63th IEA Fluidized Bed Conversion Meeting, Ponferrada, Spain, 2011.

22. Hack, H. et al., Initial operation of the CIUDEN Oxy-CFB boiler demonstration project. In 11th Annual Carbon Capture, Utilization and Sequestration Conference, Pittsburgh, Pennsylvania, USA, 2012 , p. 15.

23. Seddighi, S., Pallarès, K. D., Normann, F. and Johnsson, F., Progress of combustion in an oxy-fuel circulating fluidized-bed furnace: measurements and modeling in a $4 \mathrm{MWth}$ boiler. Energy Fuels, 2013, 27, 6222-6230.

24. Duan, L., Sun, H., Zhao, C., Zhou, W. and Chen, X., Coal combustion characteristics on an oxy-fuel circulating fluidized bed combustor with warm flue gas recycle. Fuel, 2014, 127, 47-51.

25. Li, H., Li, S., Ren, Q., Li, W., Xu, M., Liu, J. Z. and Lu, Q., Experimental results for oxy-fuel combustion with high oxygen concentration in a $1 \mathrm{MW}$ th pilot-scale circulating fluidized bed. Energy Procedia, 2014, 63, 362-371.

26. Tan, L., Li, S., Li, W., Shou, E. and Lu, Q., Effects of oxygen staging and excess oxygen on $\mathrm{O}_{2} / \mathrm{CO}_{2}$ combustion with a high oxygen concentration in a circulating fluidized bed. Energy Fuels, 2014, 28, 2069-2075.

27. Kobayashi, H. and Bool, L. E., Direct oxy-coal combustion with minimum or no flue gas recycle. In Oxy-fuel Combustion for Power Generation and Carbon Dioxide $\left(\mathrm{CO}_{2}\right)$ Capture (ed. Zheng, L.), Woodhead Publishing Limited, Cambridge, UK, 2011, p. 374.

28. US Department of Energy, Energy tips 3 - process heating, industrial heating, 2005.

29. Duan, L., Zhao, C., Zhou, W., Qu, C. and Chen, X., $\mathrm{O}_{2} / \mathrm{CO}_{2}$ coal combustion characteristics in a $50 \mathrm{kWth}$ circulating fluidized bed. Int. J. Greenhouse Gas Control, 2011, 5, 770-776.

ACKNOWLEDGEMENTS. I thank the Indian Council of Cultural Relations (ICCR) for granting scholarship to pursue $\mathrm{Ph} \mathrm{D}$ at the Indian Institute of Technology Guwahati, Guwahati, India.

Received 26 January 2017; accepted 13 April 2017

doi: $10.18520 / \mathrm{cs} / \mathrm{v} 113 / \mathrm{i} 08 / 1560-1567$ 